\title{
COMPETÊNCIAS DOCENTES COMO ANTECEDENTES DA AVALIAÇÃO DE DESEMPENHO DO PROFESSOR: PERCEPÇÃO DE MESTRANDOS DE ADMINISTRAÇÃO
}

\author{
Márcia ZAMPIERI GrohmanN* \\ MÁrCio SAMPEDRo RAmos**
}

Recebido: 12 fev. $2011 \quad$ Aprovado: 13 set. 2011

\begin{abstract}
* Doutora em Engenharia da Produção e Sistemas pela Universidade Federal de Santa Catarina. Professora Adjunta do Departamento de Ciências Administrativas da Universidade Federal de Santa Maria, Rio Grande do Sul, Brasil. E-mail: marciazg@gmail.com

** Graduando em Administração de Empresas, acadêmico do Mestrado em Administração da Universidade Federal de Santa Maria, Rio Grande do Sul, Brasil. E-mail: ramos_marcio@yahoo.com.br
\end{abstract}

Resumo: Este estudo teve como objetivo mapear competências docentes (comportamento em aula, didática e conhecimento, relacionamento, avaliação e utilidade), através da avaliação de acadêmicos do curso de mestrado em administração, e verificar suas relações causais com o desempenho dos professores (avaliação de desempenho e nota geral). Através da análise dos resultados de 99 questionários constatou-se que os professores foram bem avaliados, obtendo médias bem acima do valor intermediário da escala $(2,50)$ : comportamento em aula - 4,07; didática e conhecimento $=3,92$; relacionamento $-3,79$; avaliação e utilidade $-3,74$; desempenho $-3,73$. As relações de dependências encontradas foram: didática e conhecimento $x$ desempenho $\left(R^{2}=68,5 \%\right)$, avaliação e utilidade $x$ desempenho $\left(R^{2}=23,5 \%\right)$, comportamento $x$ desempenho $\left(R^{2}=13,4 \%\right)$, didática e conhecimento $x$ nota geral $\left(R^{2}=52,1 \%\right)$ e avaliação e utilidade $x$ nota geral $\left(R^{2}=21,4 \%\right)$. Concluiu-se que didática/conhecimento e avaliação/utilidade são os principais antecedentes do desempenho docente.

Palavras-chave: Competências docentes. Desempenho docente. Relação causal.

\section{TEACHING COMPETENCE AS TEACHING EVALUATION ANTECEDENTS: MBA STUDENTS PERCEPTIONS}

Abstract: This paper proposes to evaluate teaching competence (class behavior, methodology and knowledge, relationship, evaluation and usefulness) trough MBA students' perceptions and their causal relations with teaching evaluation. In a research with 99 responses it was observed that the teachers evaluation was good with average score higher than 2.50 (middle of scale). The average was: classes' behavior -4.07 , methodology and knowledge -3.92 , relationship -3.70 , evaluation and usefulness -3.74 . Causal relations were found in: methodology and knowledge vs. evaluation $(\beta=68.5 \%)$, evaluation and usefulness vs. evaluation $(\beta=23.5 \%)$, classes' behavior vs. evaluation $(\beta=13.4 \%)$, methodology and knowledge vs. total average $(\beta=52.1 \%)$, evaluation and usefulness vs. total average $(\beta=21.45 \%)$. These results prove that methodology/knowledge and evaluation/ usefulness are the most important antecedents of teachers' evaluation.

Keywords: Teaching competence. Teaching evaluation. Causal relation. 


\section{INTRODUÇÃO}

Entender e utilizar processos de avaliação no ensino superior é, segundo Tejedor (2003), fundamental para que, através da reflexão, aprimorem-se os mecanismos de ensino/aprendizagem. Para Zúñiga (1997) este é um processo que vai muito além da melhoria da formação de profissionais, sendo uma maneira das universidades cumprirem seu papel social, contribuindo para a criação de uma sociedade mais desenvolvida e com valores éticos.

O objeto de estudo deste artigo é a avaliação do ensino superior em nível de pós-graduação e sua escolha deve-se à grande disseminação destes cursos por todo o Brasil, tanto de forma presencial como de forma virtual (à distância).

A última reforma da educação, que entende que o modelo único (ou universidade de pesquisa) esgotou-se e é incapaz de adaptar-se às novas condições da economia mundial (BRASIL, 1996), acarretou, na década passada, o desmonte das universidades públicas. Estas universidades e seus pesquisadores foram buscar novas fontes de recursos, pois o estado aumentou sua função avaliadora e coordenadora e diminuiu sua função de mantenedora das Instituições de Ensino Superior (CATANI; OLIVEIRA, 2002; CHAUÍ, 1999a; 1999b; 1998; RISTOFF 1999; SGUISSARDI, 2000).

Ao mesmo tempo, o achatamento salarial dos professores das instituições de ensino superior públicas faz com que, segundo Chauí (1999, p. 215) "surjam uma ampla oferta de cursos pagos de especialização, que completam o salário dos professores, mas absorvem tempo e energia dos docentes, notadamente daqueles com maior titulação". Também é necessário destacar que as inovações tecnológicas, mudanças sociais, culturais e comerciais, globalização e aumento da competitividade exigem uma maior qualificação dos trabalhadores, exigindo-lhes uma educação mais adequada, e, portanto, aumentando a responsabilidade das universidades perante a sociedade.

Atualmente, os cursos de pós-graduação e seus professores, são continuamente avaliados através de índices de produtividade que envolve questões como: número de orientandos, número de horas/aula, defesas concluídas, números de projetos de pesquisa, tempo de conclusão do curso e, principalmente, a produção intelectual, através de pontuações obtidas por publicações em periódicos.

Porém, um dos aspectos ainda carentes de estudos é a forma como os discentes avaliam o trabalho dos docentes destes cursos de pós-graduação. Será que um professor "pontuado" é sinônimo de um bom professor? A avaliação 
docente pode resumir-se apenas a estes índices quantitativos? Ser um bom professor não envolve questões mais abrangentes?

Frente a esta realidade e a estes questionamentos, o presente trabalho procurou identificar qual a percepção dos alunos sobre as competências dos docentes de um curso de mestrado acadêmico em administração e, posteriormente, identificar quais destas competências causam maior impacto no desempenho destes docentes. Desta forma, o problema de pesquisa foi definido como: "Quais as principais competências docentes que influenciam no bom desempenho dos professores de pós-graduação stricto sensu?"

Os objetivos definidos no estudo foram: mapear as competências dos docentes do curso de Mestrado em Administração; avaliar o desempenho dos docentes do curso de Mestrado em Administração; verificar a existência de relações causais entre competências e desempenho para identificar quais são as competências docentes entendidas como mais importantes, pelos discentes pesquisados.

Luiz, Costa e Costa (2010) apontam que há uma carência de estudos nacionais sobre o tema de mapeamento de competências dos docentes de pósgraduação. Alguns estudos que enfocaram esta temática, de forma transversal, foram: Belloni (2000); Barroso (2002); Costa e Costa (2007); Carvalho (2001); Hanashiro e Nassif (2006); Sant'Anna (1999); Lins, Ameida e Bartholo Júnior (2004); Neves (2005). Outros estudos como os de Walter, Tontini e Domingues (2005); Loretto (2001); Abreu e Guimarães (2003); Cunha, Borges e Fachel (1998); Alves (2000); Owlia e Aspinwall (1996) buscaram mensurar a satisfação dos acadêmicos com as instituições e/ou seus docentes.

Porém, são poucos autores nacionais que utilizam, de forma explícita, o termo competências docentes, neste sentido, cita-se Masetto (2003) e Cunha (1996). Mas, tal termo é muito utilizado em trabalhos desenvolvidos na América Latina e Espanha, como, por exemplo, nos estudos de: Bozu e Herrera (2009); Galviz (2007); Alvarez e Diaz (2004); Tejedor (2003); Casassus, Arancibia e Froemel (1996); Garcia-Valcárcel (1992); Zúñiga (1997).

Desta forma, comprova-se a importância do tema e também a carência de estudos nacionais sobre competências docentes e, principalmente, não foram encontrados estudos que buscam relações causais entre competências (antecedentes) e desempenho docentes (consequente).

Para responder ao problema de pesquisa e aos objetivos propostos foi desenvolvida uma pesquisa descritiva e quantitativa baseado nos modelos teóricos utilizados por autores latino-americanos. 


\section{COMPETÊNCIAS DOCENTES}

O termo competência docente é empregado de forma direta ou indireta nos estudos que tratam de qualidade do ensino, satisfação de docentes e discentes, dentre outros. Os diversos enfoques dados ao assunto tornam a temática ampla e formada por correntes distintas. Por isto, torna-se fundamental explicitar qual o enfoque deste estudo.

A idéia de competências possui duas concepções principais: a corrente americana considera que competências é um conjunto de conhecimentos, habilidades e atitudes que afetam o desempenho dos indivíduos (inputs); a corrente européia entende que as competências são demonstradas a partir do momento em que os profissionais atingem ou superam resultados esperados em seu trabalho (outputs) (PARRY, 1996).

Neste estudo utiliza-se a concepção européia de competências e, portanto, uma das principais definições é a de Boterf (2003, p. 61) que considera ser a competência "mais uma disposição que um gesto elementar". A competência, portanto, não se limite a um estoque de conhecimento teórico e empírico que o indivíduo possui, trata-se de "um saber agir responsável e reconhecido, que implica mobilizar, integrar, transferir conhecimentos, recursos, habilidades" (FLEURY; FLEURY, 2001, p. 21).

Ampliando esta visão, Zarifian (2001), Parry (1996) e Ruas (2001) consideram que competência refere-se à capacidade de a pessoa assumir iniciativas, ir além das atividades prescritas, ser capaz de compreender e dominar novas situações de trabalho, ser responsável e ser reconhecida por isso. A competência não estaria limitada pela tarefa ou ao conhecimento ou qualificação do indivíduo, mas estaria apoiada nesses.

Dando foco na competência de docentes universitários, Cunha (1996, p. 89) argumenta que "há uma concepção de professor competente feita pela sociedade e, mais precisamente, pela comunidade escolar. É fruto do jogo de expectativas e das práticas que se aceita como melhores para a escola do nosso tempo".

Masetto (2003) considera que, num contexto universitário de construção do saber para um mundo em transformação, o docente necessita combinar imaginação e ação, buscar novas informações, saber trabalhar com tais informações, utilizar os recursos da informática para comunicar-se nacional e internacionalmente e que tenha capacidade de construir ou reconstruir conhecimento.

Tomando-se por base a divisão usual de competências - conhecimentos, habilidades e atitudes - o trabalho docente possui como principais atributos: domínio da área de conhecimento e da área pedagógica são as principais di- 
mensões do conhecimento (FREIRE, 1997; MASETTO, 2003a; PERRENOUD, 2000); criatividade, comunicação, planejamento, relacionamento interpessoal, trabalho em equipe e visão sistêmica são os principais aspectos da dimensão habilidade (FREIRE, 1997; MORAES, 1997; HESS, 1997; PERRENOUD, 2000); ética, generosidade, alegria, esperança, comprometimento, flexibilidade e humildade são os componentes fundamentais da dimensão atitude (FREIRE, 1997; MORAES, 1997; HESS, 1997).

Schon (2000) completa este pensamento afirmando que é necessário incorporar novos elementos nos sistemas educacionais que sejam capazes de transformar aprendizes passivos em gestores ativos. Para tanto é fundamental que os docentes universitários trabalhem com o ensino prático-reflexivo, oportunizando um ambiente para a criação de elos entre a escola e a pesquisa e prática profissional (SCHON, 2000).

Perrenoud (2000, p. 20-21) define dez famílias de competências acadêmicas que delineiam, de certo forma, o que o professor universitário deve ser capaz de fazer. São elas:

a) organizar e dirigir situações de aprendizagem, o que significa trabalhar a partir das aprendizagens;

b) administrar o progresso da aprendizagem, observando e avaliando os estudantes de acordo com uma abordagem formativa;

c) conceber e fazer evoluir os dispositivos de diferenciação, que consiste em um meio de desenvolver a cooperação entre os alunos e certas formas simples de ensino mútuo;

d) envolver os alunos em sua aprendizagem e em seu trabalho, como instituir e fazer funcionar um conselho de alunos e negociar com eles diversos tipos de regras e contratos;

e) trabalhar em equipe, o que se relaciona a dirigir grupos de trabalho, conduzir reuniões para que estas se tornem decisórias, administrar crises e conflitos interpessoais e enfrentar e analisar um conjunto de situações complexas, práticas e problemas profissionais;

f) participar da administração da escola, ou seja, elaborar e negociar um projeto da instituição, administrar os recursos da escola e estimular, em tal espaço, a participação dos alunos; 
g) informar e envolver os pais, por meio de reuniões de informação e de debate, da consecução de entrevistas e promover o envolvimento dos pais na construção dos saberes;

h) utilizar novas tecnologias, explorando as potencialidades didáticas dos programas em relação aos objetivos do ensino e utilizando-se de ferramentas de multimídia no ensino;

i) enfrentar os deveres e dilemas éticos da profissão, o que consiste em previnir a violência escolar, lutar contra preconceitos e as discriminações sexuais, étnicas e sociais e desenvolver o senso de responsabilidade, solidariedade e o sentimento de justiça;

j) administrar sua própria formação contínua, sabendo explicitar as próprias práticas e estabelecendo seu próprio balanço de competências e seu programa de formação contínua.

\section{Figura 1 - Modelos de Avaliação de Competências Docentes}

\begin{tabular}{|c|c|c|c|c|c|}
\hline $\begin{array}{l}\text { Trent e Cohen } \\
\text { (1973) }\end{array}$ & Marsch (1987) & $\begin{array}{c}\text { Frey, Leonard e } \\
\text { Beatty (1975) }\end{array}$ & $\begin{array}{c}\text { Ramsden } \\
\text { (1991) }\end{array}$ & Tejedor (1993) & $\begin{array}{c}\text { Garcia-Ramos } \\
\text { (1996) }\end{array}$ \\
\hline $\begin{array}{l}\text { 1. Organização } \\
\text { e clareza nas } \\
\text { explicações }\end{array}$ & $\begin{array}{l}\text { 1. Aprendiza- } \\
\text { gem/valor }\end{array}$ & $\begin{array}{l}\text { 1. Elogios dos } \\
\text { alunos }\end{array}$ & $\begin{array}{l}\text { 1. Metodologia } \\
\text { adequada }\end{array}$ & $\begin{array}{l}\text { 1. Cumprimen- } \\
\text { to das obriga- } \\
\text { ções }\end{array}$ & $\begin{array}{l}\text { 1. Programação } \\
\text { e organização } \\
\text { das aulas }\end{array}$ \\
\hline $\begin{array}{l}\text { 2. Atitude } \\
\text { positiva } \\
\text { durante as aula }\end{array}$ & $\begin{array}{l}\text { 2. Interação } \\
\text { com o grupo }\end{array}$ & $\begin{array}{l}\text { 2. Discussão em } \\
\text { aula }\end{array}$ & $\begin{array}{l}\text { 2. Clareza nos } \\
\text { objetivos da } \\
\text { disciplina }\end{array}$ & $\begin{array}{l}\text { 2. Clareza e } \\
\text { cumprimento } \\
\text { do programa }\end{array}$ & $\begin{array}{l}\text { 2. Domínio do } \\
\text { conteúdo e } \\
\text { clareza na } \\
\text { explicação }\end{array}$ \\
\hline $\begin{array}{l}\text { 3. Estimular o } \\
\text { interessee } \\
\text { motivação dos } \\
\text { alunos }\end{array}$ & $\begin{array}{l}\text { 3. Ajuda } \\
\text { individual }\end{array}$ & $\begin{array}{l}\text { 3. Atenção } \\
\text { pessoal }\end{array}$ & $\begin{array}{l}\text { 3. Adequada } \\
\text { carga de } \\
\text { trabalho }\end{array}$ & $\begin{array}{l}\text { 3. Domínio do } \\
\text { conteúdo }\end{array}$ & $\begin{array}{l}\text { 3. Motivação } \\
\text { ao aprendizado }\end{array}$ \\
\hline $\begin{array}{l}\text { 4. Dar atenção } \\
\text { individual aos } \\
\text { alunos }\end{array}$ & $\begin{array}{l}\text { 4. Carga de } \\
\text { trabalho e } \\
\text { dificuldade }\end{array}$ & 4. Qualificações & $\begin{array}{l}\text { 4. Adequada } \\
\text { avaliação }\end{array}$ & $\begin{array}{l}\text { 4. Interação } \\
\text { com os alunos }\end{array}$ & $\begin{array}{l}\text { 4. Interação } \\
\text { com os alunos }\end{array}$ \\
\hline \multirow[t]{5}{*}{ 5. Entusiasmo } & $\begin{array}{l}\text { 5. Exames e } \\
\text { avaliações }\end{array}$ & $\begin{array}{l}\text { 5. Carga de } \\
\text { trabalho }\end{array}$ & $\begin{array}{l}\text { 5. Estímuloe } \\
\text { motivação aos } \\
\text { alunos }\end{array}$ & $\begin{array}{l}\text { 5. Recursos } \\
\text { utilizadose } \\
\text { prática }\end{array}$ & $\begin{array}{l}\text { 5. Atenção } \\
\text { individual ao } \\
\text { aluno }\end{array}$ \\
\hline & $\begin{array}{l}\text { 6. Organização } \\
\text { e clareza }\end{array}$ & $\begin{array}{l}\text { 6. Clareza nas } \\
\text { explicações }\end{array}$ & & 6. Avaliações & $\begin{array}{l}\text { 6. Exames e } \\
\text { avaliações }\end{array}$ \\
\hline & 7. Entusiasmo & $\begin{array}{l}\text { 7. Organização e } \\
\text { planificação }\end{array}$ & & & \\
\hline & $\begin{array}{l}\text { 8. Amplitude no } \\
\text { enfoque }\end{array}$ & & & & \\
\hline & $\begin{array}{l}\text { 9. Trabalho } \\
\text { extra-classes }\end{array}$ & & & & \\
\hline
\end{tabular}

Fonte: adaptado de Garcia-Ramos (1997) 
Partindo desta idéia, e transpondo-a especificamente para a realidade dos professores universitários, a Figura 1 aponta os modelos de mensuração de competências docentes que foram utilizados para a construção do instrumento do presente estudo. Como se pode observar, os autores apresentam construtos com nomes distintos, mas em suma, a idéia por traz dos modelos é muito similar e grande parte dos autores utiliza, no mínimo, os construtos: organização e planejamento das aulas, relacionamento com os alunos, estimulo e motivação à aprendizagem, domínio do conteúdo, metodologias adequadas de transmissão do conhecimento, avaliações adequadas e cumprimento das obrigações.

Ciente da similaridade dos principais modelos de mensuração optou-se por utilizar como modelo principal de pesquisa o trabalho de Garcia-Ramos (1997), com algumas adaptações para que fossem englobadas questões utilizadas em outros modelos. Desta forma, as competências docentes que foram utilizadas neste estudo receberam a seguinte nomenclatura: didática, conhecimento, ambiente de aprendizagem, relacionamento, avaliações e obrigações. A Figura 2 apresenta os respectivos itens que foram utilizados para mensurar cada uma das competências docentes na parte empírica deste artigo.

Figura 2 - Construtos de Competências Docentes Utilizados na Pesquisa

\begin{tabular}{|l|l|}
\hline FATOR & VARIÁVEIS \\
\hline Didática & v1; v2; v3; v8; v11; v30; v31 \\
\hline Conhecimento & v4; v5 \\
\hline Ambiente de Aprendizagem & v6; v7; v9; v10; v13; v14; v15 \\
\hline Relacionamento & v12; v16; v17; v18; v19; v20; v28 \\
\hline Avaliações & v21; v22; v23; v24 \\
\hline Obrigações & v25; v16; v29 \\
\hline
\end{tabular}

Fonte: elaborado pelos autores

\section{MÉTODO}

O estudo tem caráter descritivo e quantitativo. A população foi composta pelos alunos regulares do Mestrado Acadêmico em Administração que estavam realizando disciplinas no segundo semestre de 2010. Assim, a população era composta 30 alunos e buscou-se realizar um censo, porém, foram obtidas res- 
postas de 26 alunos. Como cada respondente avaliou os quatro professores do semestre que cursavam, foram obtidos, ao final da coleta de dados 104 questionários. Destes, cinco foram excluídos por erros de preenchimento ou questões em branco e, portanto, o número final de questionários válidos foi de 99.

Para a coleta de dados foi utilizado um questionário composto por 42 questões. A primeira parte do questionário era formada por cinco perguntas sobre o perfil do entrevistado (sexo, idade, trabalho, curso de graduação, área de preferência). Numa segunda etapa estavam as trinta e uma questões referentes às competências docentes, seguidas de cinco questões que avaliavam o desempenho do professor e, ao final do questionário, mais uma questão com a nota final obtida pelo professor. Nas questões de mensuração do perfil dos entrevistados foram utilizadas escalas nominais e ordinais e nas questões de mensuração das competências docentes e do desempenho docente, foram utilizadas escala Likert de cinco pontos para o grau de concordância $(1=$ discordo totalmente; $5=$ concordo totalmente). Por fim, para realizar a avaliação final do professor, foi solicitado que os respondentes atribuíssem uma nota de 0 a 10 .

A Figura 3 apresenta o desenho da pesquisa e sumariza os procedimentos utilizados.

Figura 3 - Desenho da Pesquisa

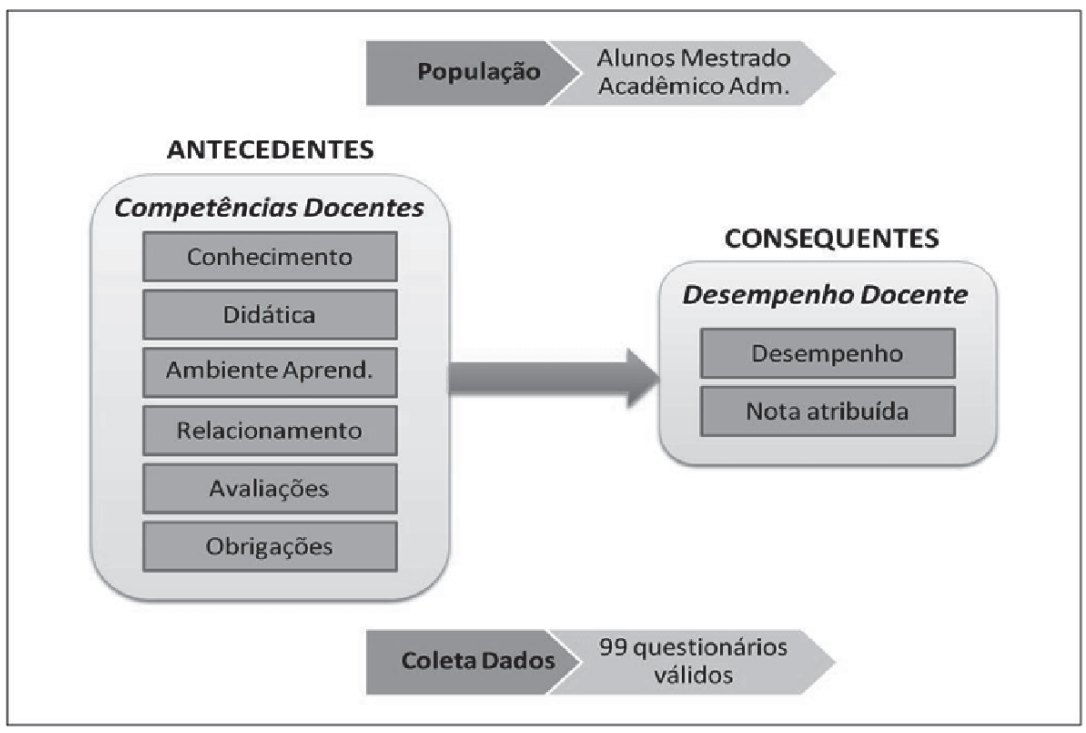

Fonte: elaborado pelos autores 
Os dados foram analisados com o apoio de dois softwares estatísticos: SPSS (Statistical Packge for Social Science) e Amos. O primeiro software (SPSS) foi utilizado para as análises da amostra (cálculos de freqüências), análise fatorial exploratória e indicadores de consistência interna (alpha de Cronbach) e, por fim, para o agrupamento dos fatores e posterior cálculo de médias e desvios-padrão. A etapa seguinte, realizada através do software Amos, buscou identificar as correlações entre os construtos antecedentes (competências docentes e, posteriormente, as relações causais entre os construtos antecedentes (competências docentes) e o construto consequente (desempenho) e, para tanto, foram realizadas regressões múltiplas.

\section{RESULTADOS}

Em relação ao perfil dos respondentes, $57,7 \%$ dos acadêmicos pertence ao gênero feminino e $42,3 \%$ ao gênero masculino, apontando uma pequena predominância de mulheres na formação da amostra.

Quanto à faixa etária, comprovou-se a juventude dos respondentes, visto que $50 \%$ da amostra foi formada por pessoas com menos de 25 anos. Na sequência, as faixas etárias encontradas foram: $19,2 \%$ entre 26 a 30 anos; $11,5 \%$ entre 31 a 35 anos; e 19,2\% com mais de 36 anos. A média de idade foi de 24,4 anos e a amplitude de 20 anos (menor idade 21 anos e maior idade 41 anos).

A grande maioria dos respondentes $(63,6 \%)$ possui dedicação integral ao curso, não realizando nenhuma atividade profissional neste período. Ao contrário, apenas uma minoria, representando $14,3 \%$ dos respondentes, possui formação em administração, ou seja, os alunos do mestrado acadêmico de administração são, em sua maioria, oriundos de outros cursos de graduação.

Por fim, quanto às linhas de interesse da preferência dos respondentes, elencaram-se as quatro áreas que são trabalhadas no curso (finanças, marketing, estratégia e recursos humanos). Observou-se que a área apontada como de maior interesse pelos respondentes foi a de recursos humanos, com 45,5\% de preferência. Em seguida aparece a área de estratégia (22,7\% da preferência) e marketing $(18,2 \%)$. A área com menor preferência foi a de finanças, com $13,9 \%$ de preferência.

\subsection{Competências Docentes}

Para a análise fatorial exploratório das competências docentes, foram utilizadas as 31 primeiras variáveis do modelo de mensuração. O objetivo desta etapa 
foi agrupar os itens em fatores e verificar se tal agrupamento iria se comportar de maneira similar àquele proposto pela literatura (Figura 2).

Utilizou-se, para a extração dos fatores, o método dos componentes principais e adequação da fatorial exploratória foi verificada através dos índices KMO (Kaiser-Meyer-Olkin) de esfericidade de Barlet. O valor obtido para o KMO foi de 0,881 e o teste de esfericidade de Barlet foi significativo e com valor de 1970,430, desta forma, comprovou-se a adequação da fatorial, pois segundo Pestana e Gageiro (2003) o valor do KMO deve ser superior a 0,60 e o teste de Barlet deve ser significativo.

Seguindo as recomendações de Hair et al (2005), utilizou-se o procedimento de exclusão de itens com comunalidades inferiores a 0,50 e, com isto, os itens v23 (faz feedback das avaliações realizadas), v24 (é objetivo e justo nas notas), v25 (está presente em todas as aulas agendadas) e v14 (utiliza várias formas de comunicação e tecnologias nas aulas) foram excluídos. Optou-se, também, pela exclusão de itens com cargas fatoriais inferiores a 0,50 , o que originou a exclusão de mais dois itens: v28 (esclarece as dúvidas dos alunos) e v15 (incentiva o estudo extra-classe).

$\mathrm{Na}$ extração dos fatores, utilizou-se os critérios de autovalor maior que $1 \mathrm{e}$ de total da variância explicada. Obtiveram-se quatro fatores que, em conjunto, explicam $67,37 \%$ do total da variância encontrada, valor considerado satisfatório pois foi superior aos $60 \%$ considerados como limite aceitável. A tabela 1 apresenta as variâncias explicadas por cada um dos quatro fatores.

Para verificar a consistência interna dos fatores, foi utilizado o teste de confiabilidade alpha de Cronbach que deve apresentar valores superiores a 0,70 para representarem confiabilidade satisfatória da consistência interna do modelo utilizado (HAIR et al, 2005). Os quatro fatores apresentaram valores acima de 0,80 , o que denota uma consistência interna muito boa. $\mathrm{O}$ fator didática e conhecimento obteve alpha de 0,939 ; o fator relacionamento obteve alpha de 0,885 ; o fator comportamento em aula obteve alpha de 0,841 e o fator avaliação e utilidade obteve alpha de 0,801 . O instrumento como um todo obteve um alpha de Cronbach de 0,939, atestando sua excelente consistência interna.

A Tabela 1 apresenta os resultados da análise fatorial exploratória para as competências docentes. Observou-se que os fatores originais, propostos pela teoria, não foram confirmados na prática, pois vários itens trocaram de lugar e dos seis fatores iniciais foram confirmados apenas quatro. Houve a aglutinação do construto didática e do construto conhecimento, bem como os construtos avaliação e obrigações profissionais também foram unidos e incluiu-se dois itens originários do fator didática. 


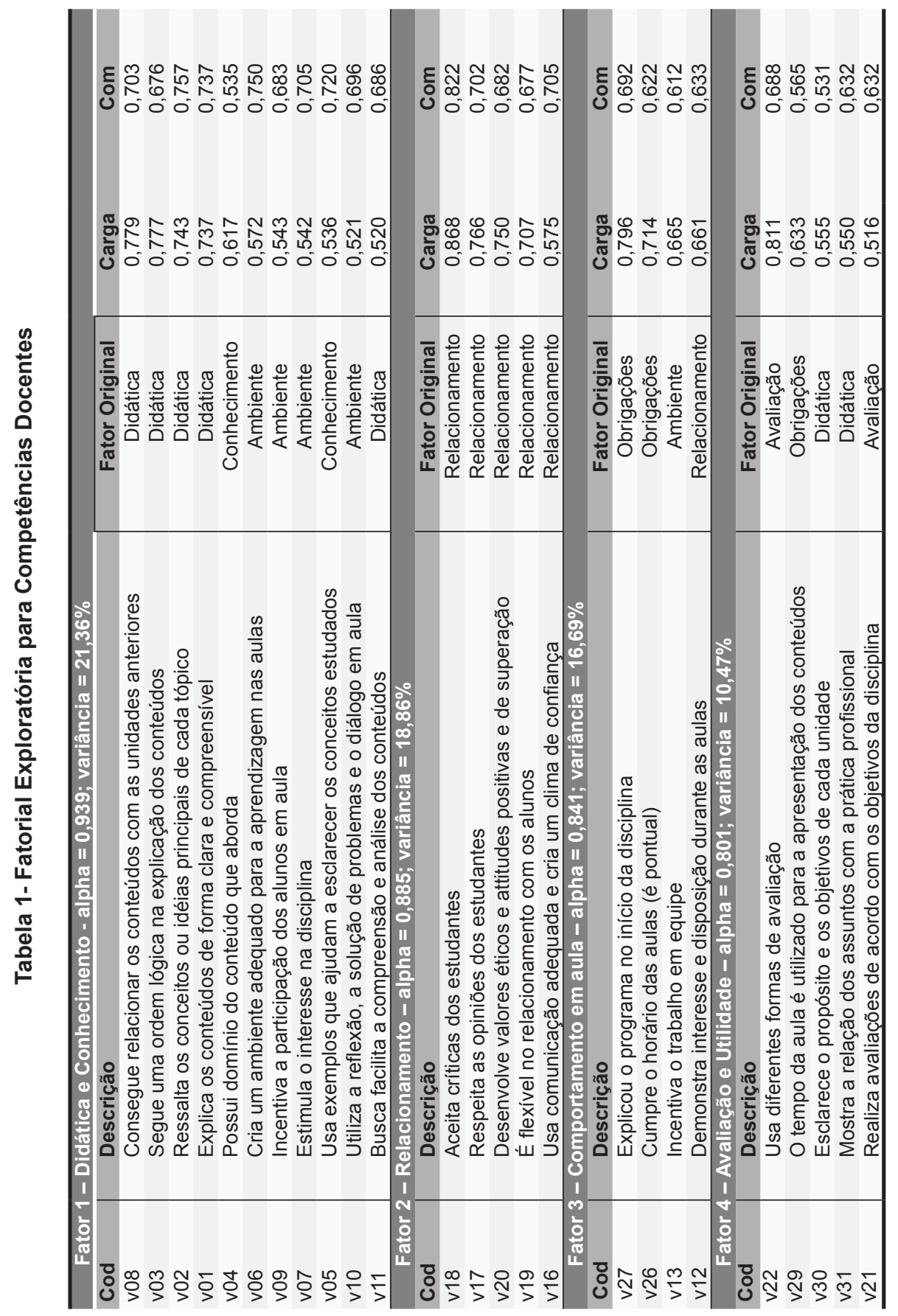


O fator 1, denominado de Didática e Conhecimento foi formado por onze itens provenientes dos construtos teóricos didática, conhecimento e ambiente de aprendizagem. $\mathrm{O}$ fator obteve o maior alpha entre os construtos $(0,939) \mathrm{e}$ foi o responsável por explicar $21,36 \%$ da variância total. No fator 2 ficaram apenas itens originários do construto Relacionamento, desta forma, os cinco itens do fator explicaram $18,86 \%$ da variância total e seu alpha foi de 0,885 . O terceiro fator, que passou a ser chamado de Comportamento em Aula, foi o que apresentou itens mais variados e, portanto, sua denominação foi a mais complexa. Duas variáveis vieram do construto obrigações profissionais, outra veio de ambiente de aprendizagem e a última do construto relacionamento. Este fator obteve um falha de 0,841 e explicou $16,69 \%$ da variância total. Por fim, o quarto fator, denominado de Avaliação e Utilidade explicou 10,47\% da variância total, obteve o menor alpha $(0,801)$, porém um valor bem satisfatório, e foi formado por cinco variáveis oriundas dos construtos avaliação (duas), didática (duas) e obrigações profissionais (uma).

A próxima etapa de análise dos dados referentes às competências docentes foi o da transformação das diferentes variáveis que formavam cada fator em uma nova variável. Tal procedimento consiste no cálculo da média das variáveis que formam cada fator e é a base para que as relações de dependência (regressões múltiplas) entre os construtos (Tabela 2).

Tabela 2 - Estatística Descritiva das Competências Docentes

\begin{tabular}{l|c|c}
\hline Fator & Média & Desvio-padrão \\
\hline Didática e Conhecimento & 3,92 & 0,795 \\
Relacionamento & 3,79 & 0,796 \\
Comportamento em aula & 4,07 & 0,844 \\
Avaliação e Utilidade & 3,74 & 0,683 \\
\hline
\end{tabular}

Considerando-se as médias dos fatores observa-se que o construto comportamento em aula foi o que obteve maior média $(4,07)$, desta forma, os acadêmicos consideram que os professores do curso de mestrado em administração possuem um comportamento que estimula os alunos, demonstrando interesse e entusiasmo durante as aulas. O segundo fator com maior média $(3,92)$ foi o da didática e conhecimento, o valor obtido pelo fator demonstra que os professores do curso possuem conhecimento sobre os conteúdos ministrados e também utilizam métodos didáticos que satisfazem os alunos. Em seguida, aparece o construto Relacionamento, com média de 3,79, resultado que aponta o bom relacionamento dos professores do curso com os acadêmicos. O fator com 
menor média foi o de avaliação e utilidade (média de 3,74), porém, não pode se afirmar que há diferença estatística entre esta média e a do fator relacionamento.

Em suma, as médias encontradas nos fatores foram altamente satisfatórias, pois utilizando-se a metade da escala como parâmetro de comparação, procedimento apregoado por Nunnally (1978), observa-se que todos os fatores obtiveram médias bem superiores a 2,50, demonstrando que os acadêmicos do mestrado em administração consideram que seus professores possuem competências docentes bem acima do satisfatório.

\subsection{Avaliação do Desempenho Docente}

A análise fatorial para a avaliação do desempenho docente foi com as cinco variáveis propostas no modelo teórico de mensuração. Através dos critérios de comunalidades inferiores a 0,50 , cargas fatoriais inferiores a 0,50 e exclusão de item para a melhoria do alpha de Cronbach, observou-se que nenhum dos itens precisou ser excluído.

Desta forma, como aponta a tabela 3, o desempenho docente apresentou estrutura unifatorial, formada por cinco itens que respondem por $77,51 \%$ da variância total encontrada e com alpha de 0,925 que atesta a excelente confiabilidade do modelo utilizado.

Tabela 3 - Fatorial Exploratória para Desempenho Docente

\begin{tabular}{|c|c|c|c|c|}
\hline Cod & Descrição & Fator Original & Carga & Com \\
\hline v34 & Estou satisfeito com o trabalho desse professor & Desempenho & 0,914 & 0,836 \\
\hline v32 & Os objetivos da disciplina estão sendo alcançado & Desempenho & 0,907 & 0,823 \\
\hline v36 & $\begin{array}{l}\text { A disciplina está satisfazendo minhas } \\
\text { expectativas iniciais }\end{array}$ & Desempenho & 0,890 & 0,793 \\
\hline v35 & $\begin{array}{l}\text { Gostaria de fazer outra disciplina com esse } \\
\text { professor }\end{array}$ & Desempenho & 0,876 & 0,767 \\
\hline v33 & Estou aprendendo com esse professor & Desempenho & 0,811 & 0,658 \\
\hline
\end{tabular}

Da mesma forma que na avaliação dos resultados das competências docentes, ocorreu a transformação das diferentes variáveis do fator em uma única variável. Outro resultado utilizado nesta análise foi o das médias nas notas atribuídas ao professor pelos acadêmicos do mestrado em administração (Tabela 4). 
Tabela 4 - Estatística Descritiva do Desempenho Docente

\begin{tabular}{l|c|c}
\hline Fator & Média & Desvio-padrão \\
\hline Avaliação do Desempenho & 3,73 & 1,016 \\
Nota Final do Professor & 7,60 & 1,887 \\
\hline
\end{tabular}

A média obtida no fator avaliação do desempenho foi de 3,73, apontando que os alunos encontram-se satisfeitos com seus professores. Por fim, a avaliação final do professor, feita através de uma nota única atribuída pelo aluno (variando de 0 a 10), foi de 7,60, ou seja, novamente os valores encontrados estão bem acima da metade das escalas utilizadas.

\subsection{Influências das Competências Docentes no Desempenho do Professor}

Buscando-se identificar as relações entre os construtos antecedentes, ou seja, os quatro fatores que mensuram competência docente (didática e conhecimento, relacionamento, comportamento em aula e avaliação e utilidade), forma realizadas correlações entre os fatores. Utilizando-se a escolha default do software Amos, foram realizadas correlações de Pearson.

\section{Tabela 5 - Correlações entre os Fatores Antecedentes (Competências Docentes)}

\begin{tabular}{|c|c|c|c|c|c|}
\hline \multicolumn{2}{|l|}{ Relação } & Valor pad. & S.E. & C.R. & $\boldsymbol{P}$ \\
\hline Didática & <--> Avaliação & 0,662 & 0,065 & 5,462 & *** \\
\hline Didática & <--> Comportamento & 0,641 & 0,080 & 5,345 & *** \\
\hline Relacionamento & <--> Comportamento & 0,581 & 0,078 & 4,974 & *** \\
\hline Relacionamento & <--> Avaliação & 0,579 & 0,063 & 4,962 & $* * *$ \\
\hline Comportamento & <--> Avaliação & 0,589 & 0,067 & 5,025 & *** \\
\hline Didática & <--> Relacionamento & 0,714 & 0,078 & 5,752 & *** \\
\hline
\end{tabular}

$* * *$ significativo a $1 \%$

A Tabela 5 aponta os resultados obtidos e, conforme se observa, todas as correlações foram positivas e estatisticamente significativas. A maior correlação encontrada foi entre o fator didática e o fator relacionamento $(71,4 \%)$, desta forma quanto melhor avaliado o docente foi no quesito didática, maior 
foi sua avaliação do quesito relacionamento. A segunda maior correlação foi entre didática e avaliação, encontrando-se uma correspondência de $66,2 \%$;;em seguida aparece a correlação entre didática e comportamento em sala de aula, com $64,1 \%$; comportamento em sala de aula e avaliação, com 58,9\%; relacionamento e comportamento em sala de aula, com 58,1\%; e, por fim, relacionamento e avaliação, com 57,9\%. Estes dados servem para corroborar com a consistência do modelo utilizado.

Para a identificação das relações causais entre os fatores antecedentes (didática, relacionamento, comportamento e avaliação) com os fatores consequentes (desempenho e nota geral), foi realizado o procedimento de regressões múltiplas. A Tabela 6 apresenta estes resultados.

Tabela 6 - Regressões entre os Fatores Antecedentes e Consequentes

\begin{tabular}{lll|c|c|c|c}
\hline \multicolumn{1}{c|}{ Relação } & & $R^{2}$ & S.E. & C.R. & $P$ \\
\hline Nota geral & $<---$ & Didática & 0,521 & 2,360 & 5,241 & $* * *$ \\
Desempenho & $<---$ & Didática & 0,685 & 0,101 & 8,692 & $* * *$ \\
Desempenho & $<---$ & Relacionamento & $-0,102$ & 0,090 & $-1,445$ & 0,148 \\
Desempenho & $<---$ & Comportamento & 0,134 & 0,080 & 2,027 & 0,043 \\
Desempenho & $<---$ & Avaliação & 0,235 & 0,100 & 3,499 & $* * *$ \\
Nota geral & $<---$ & Relacionamento & 0,048 & 2,119 & 0,538 & 0,590 \\
Nota geral & $<---$ & Comportamento & 0,119 & 1,864 & 1,427 & 0,154 \\
Nota geral & $<---$ & Avaliação & 0,214 & 2,340 & 2,525 & 0,012 \\
\hline
\end{tabular}

$* * *$ significativo a $1 \%$

Observa-se que, para um intervalo de confiança de $95 \%(\mathrm{p}<0,050)$, cinco relações de dependência foram significativas. As três relações que não foram comprovados ocorreram entre os fatores: desempenho $\mathrm{x}$ relacionamento $(\mathrm{p}=0,148)$; relacionamento $\mathrm{x}$ nota geral $(\mathrm{p}=0,590)$; comportamento $\mathrm{x}$ nota geral $(\mathrm{p}=0,154)$.

Três fatores interferem, de forma significativa, no desempenho docente. O fator que apresenta maior grau de relação é Didática e Conhecimento, com um grau positivo de dependência de $68,5 \%$, ou seja, quanto melhor o docente foi avaliado quanto ao conhecimento que possui e a didática que utiliza, maior foi o grau de satisfação com o desempenho do mesmo. O segundo fator que apresentou maior grau de dependência foi Avaliação e Utilidade, apresentando 
um grau de dependência na ordem de $23,5 \%$, o que significa que quanto melhor a avaliado neste quesito, maior o grau de satisfação com o desempenho do professor. Por fim, o último fator que interferiu no desempenho docente foi a comportamento em sala de aula, representando uma relação de $13,4 \%$, desta forma, quanto melhor comportamento o professor apresentou, melhor foi avaliação que recebeu. Um resultado interessante e que merece ser ressaltado é a não relação significativa entre relacionamento com desempenho, ou seja, os respondentes não consideraram que quanto melhor era o relacionamento do docente com os alunos, melhor era seu desempenho.

Quanto à nota geral atribuída ao professor, observa-se que foram encontradas duas relações positivas e significativas. $\mathrm{O}$ fator com maior relação foi Didática e Conhecimento, num grau de dependência de $52,1 \%$, segundo maior valor encontrado entre todas as relações testadas. $\mathrm{O}$ outro fator que apresentou relação de dependência com a nota geral do professor foi o de Avaliação e Utilidade, apresentando um grau de dependência na ordem de $21,4 \%$.

A Figura 4 apresenta o resumo de todos os resultados encontrados nesta última etapa da análise dos dados. As setas com pontas duplas representam as correlações entre os fatores antecedentes e as setas retas e com ponta única representam as relações causais entres os antecedentes (competências docentes) e os consequentes (desempenho docente).

Figura 4 - Resultados das Equações Estruturais

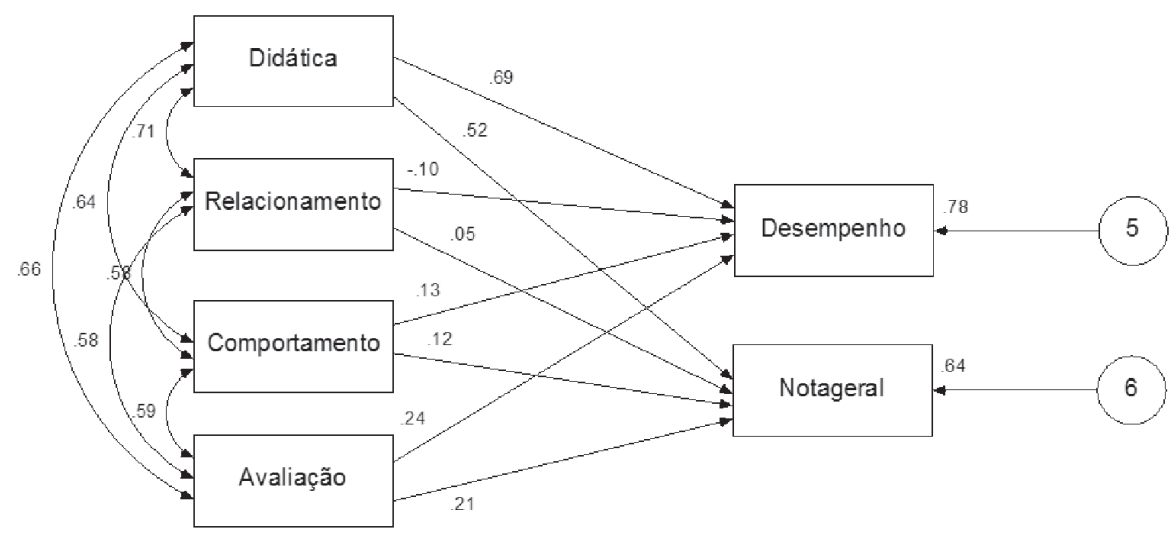

Fonte: elaborado pelos autores

Salienta-se que em ambos os casos (desempenho ou nota geral como fator consequente) os principais fatores antecedentes foram, em ordem de importân- 
cia, Didática e Conhecimento e Avaliação e Utilidade. Estes dados apontam que na percepção dos mestrandos pesquisados, um bom professor deve ter, acima de tudo, domínio do conteúdo que ministra e uma boa didática para transmitilo aos alunos; e realizar avaliações justas, mostrando a utilidade prática do conteúdo que é ministrado.

\section{CONSIDERAÇÕES FINAIS}

O presente estudo centrou-se em procurar uma resposta para o seguinte problema de pesquisa: "Quais as principais competências docentes que influenciam no bom desempenho dos professores de pós-graduação stricto sensu?". A pesquisa partiu de um modelo teórico que mapeava as seguintes competências docentes: didática, conhecimento, ambiente de aprendizagem, relacionamento, avaliações e obrigações. Os resultados apontaram que, dentre estas competências, as que mais influenciaram no desempenho docente foram didática/conhecimento e avaliação/prática, respondendo, assim ao problema de pesquisa.

Pautando-se na visão européia de competências, o estudo apresentou vários modelos para mensuração de competências de docentes universitários e aglutinou tais idéias em um instrumento que foi validade e com confiabilidade atestada estatisticamente.

Com relação aos resultados, pôde-se observar que a competência que obteve maior média foi comportamento em aula $(4,07)$, a segunda competência com maior média $(3,92)$ foi o da didática e conhecimento, em seguida, aparece o construto relacionamento, com média de 3,79 , e, por fim, avaliação e utilidade (média de 3,74). Tais dados apontam uma avaliação docente altamente satisfatórias, (escala de 5 pontos), demonstrando que os acadêmicos do mestrado em administração consideram que seus professores possuem competências docentes bem acima da média $(2,50)$. Estas informações demonstram que o primeiro objetivo do estudo - mapear as competências dos docentes do curso de Mestrado em Administração - foi atingido.

Em termos da avaliação do desempenho docente, verificou-se que o construto obteve uma média final de 3,73 (escala de 1 a 5) e a avaliação final do professor, feita através de uma nota única atribuída pelo aluno (variando de 0 a 10), foi de 7,60. Desta forma, respondeu-se ao segundo objetivo da pesquisa - avaliar o desempenho dos docentes do curso de Mestrado em Administração - e comprou-se que os alunos encontram-se satisfeitos com seus professores.

Por fim, o terceiro e principal objetivo era o de verificar a existência de relações causais entre competências e desempenho para identificar quais são 
competências docentes entendidas como mais importantes pelos discentes pesquisados. O desempenho do professor foi influenciado por três fatores: didática/ conhecimento, com um grau positivo de dependência de $68,5 \%$; avaliação/utilidade, apresentando um grau de dependência de $23,5 \%$; e comportamento em sala de aula, representando uma relação de 13,4\%. Quanto à nota geral atribuída ao professor, as relações de dependência foram: didática/conhecimento, num grau de dependência de 52,1\%; e avaliação/utilidade, apresentando um grau de dependência na ordem de $21,4 \%$.

Como limitação do estudo, cita-se o fato de que o tema competência está em evidência, porém ainda carece de uma nomenclatura com entendimento único e de investigações empíricas, como a abordagem da temática do presente artigo. O procedimento de mapear competências de docentes universitários é incipiente no Brasil, apesar de haver um considerável número de pesquisas na América Latina e Espanha. Por fim, é necessário salientar que todas as conclusões são pautadas pela percepção dos acadêmicos pesquisados e, nem sempre, a forma como o aluno percebe um bom professor é a mais adequada, pois alguns discentes não possuem maturidade suficiente, porém, tentou-se minimizar tal limitação pesquisando-se alunos de mestrado que, teoricamente, são pessoas com maior experiência e maturidade.

\section{REFERÊNCIAS}

ABREU, M. F. D. V.; GUIMARÃES, T. A. Satisfação com o ensino superior de administração: o ponto de vista de discentes de IES privadas do Distrito Federal. In: ENCONTRO NACIONAL DE PROGRAMAS DE PÓS-GRADUAÇÃO EM ADMINISTRAÇÃO, 27., 2003, Atibaia. Anais... Atibaia: ENANPAD 2003. CD ROM.

ALVAREZ, R. A.; DIAZ, M. J. F. La percepción de los estudiantes universitarios en la competencia docente: validación de una escala. Revista Educación, Madrid, v. 28, n. 2, p.145-166, 2004.

ALVES, H. M. B. As dimensões da qualidade no serviço educação. Revista Portuguesa de Gestão, Lisboa, out. 2000.

BARROSO, M. F. C. M. Análise multicritério e avaliação de desempenho docente sob a ótica do corpo discente em instituições de ensino superior. 2002. Dissertação (Mestrado em Engenharia de Produção) - Universidade 
Estadual do Norte Fluminense Darcy Ribeiro, Campos dos Goytacazes, 2002.

BELLONI, J. A. Uma metodologia de avaliação da eficiência produtiva de universidades federais brasileiras. 2000. $245 \mathrm{f}$. Tese (Doutorado em Engenharia de Produção e Sistemas) - Universidade Federal de Santa Catarina, Florianópolis, 2000.

BOTERF, G. L. Desenvolvendo a competência dos profissionais. Porto Alegre: Bookman, 2003.

BOZU, Z.; HERRERA, P. J. C. El profesorado universitario en la sociedad del conocimiento: competências profesionales docentes. Revista de

Formación e Innovación Educativa Universitaria, Vigo, v. 2, n. 2, p. 8797, 2009.

BRASIL. Congresso Nacional. Lei n ${ }^{\circ}$ 9.394, de 20 de dezembro de 1996. Estabelece as diretrizes e bases da educação nacional. Diário Oficial da União, Brasília, 1996.

CARVALHO, A. M. A Monitoramento e avaliação da pós-graduação: algumas reflexões sobre requisitos e critérios. Psicol. USP, São Paulo, v. 12, n. 1, p. 203-221, 2001.

CASASSUS, J.; ARANCIBIA, V.; FROEMEL, J. E. Laboratorio latinoamericano de evaluación de la calidad de la educación. Revista Iberoametricana de Educación, Madri, v. 10, p. 247-259, 1996.

CATANI, A.; OLIVEIRA, J. Educação superior no Brasil. Petrópolis: Vozes, 2002.

CHAUI, M. A universidade em ruínas. In: TRINDADE, H. Universidade em ruínas na república dos professores. Petrópolis: Vozes, 1999a.

CHAUI, M. Universidade em liquidação. Folha de S. Paulo, São Paulo, v. 11, n. 7, 1999b.

CHAUI, M. A universidade hoje. Praga - Revista de Estudos Marxistas, São Paulo, v. 6, p. 23-32, 1998.

COSTA, E. L. C.; COSTA, H. G. Modelo para mapeamento de lacunas de percepção no negócio de e-procurement. In: ENCONTRO NACIONAL DE 
ENGENHARIA DE PRODUÇÃO, 27., 2007, Foz do Iguaçu. Anais... Foz do Iguaçu: ABEPRO, 2007.

CUNHA, M. I. O bom professor e suas práticas. Campinas: Papirus, 1996.

CUNHA, M. V. M. J.; BORGES, A. A. J.; FACHEL, J. M. G. Esquema CFB para a mensuração da satisfação de clientes: uma proposta conceitual e prática. In: ENCONTRO NACIONAL DE PROGRAMAS DE PÓSGRADUAÇÃO EM ADMINISTRAÇÃO, 22., 1998, Foz do Iguaçu. Anais... Foz do Iguaçu: ENANPAD 1998. CD-ROM.

FLEURY, M. T. L.; FLEURY, A. Construindo o conceito de competência. Revista de Administração Contemporânea - RAC, Rio de Janeiro, v. 2, p. 183-196, 2001.

FREIRE, P. Pedagogia da Esperança. São Paulo: Paz e Terra, 1997.

GALVIZ, R. V. De un perfil docente tradicional a un perfil docente basado em competencias. Acción Pedagógica, San Cristóbal, v. 16, p. 48-57, 2007.

GARCIA-RAMOS, J. M. Valoración de la competência docente del profesor universitario. Revista Complutense de Educación, Madri, v. 8, n. 2, p. 81108, 1997.

GARCIA-VALCÁRCEL, A. Características del buen profesor universitario según estusiantes y profesores. Revista de Investigación Educativa, Murcia, v. 19, p. 31-50, 1992.

HESS, D. Social studies of science. New York: University Press, 1997.

HAIR, J. F., ANDERSON, R. E., TATHAM, R. L., BLACK, W. C. Análise multivariada de dados. 5. ed. Porto Alegre: Bookman, 2005.

HANASHIRO, D. M.; NASSIF, V. M. Competências de professores: um fator competitivo. RBGN, São Paulo, v. 8, n. 20, p. 45-56, 2006.

LINS, M. P. E.; ALMEIDA, B. F.; BARTHOLO JUNIOR, R. Avaliação de desempenho na pós-graduação utilizando a análise envoltória de dados: o caso da engenharia de produção. Revista Brasileira de Pós-Graduação, Brasília, v. 1, n. 1, p. 41-56, jul. 2004. 
LORETTO, P. Q. R. Jornadas pedagógicas 2001. Disponível em: <www. isec.pt>. Acesso em: 17 dez. 2009.

LUIZ, N. M; COSTA, A. F.; COSTA, H. G. Influências da graduação em engenharia de produção no perfil dos seus egressos: percepções discentes. Avaliação, Campinas, Sorocaba, v. 15, n. 1, p. 101-120, mar. 2010.

MASSETTO, M. T. Competência pedagógica do professor universitário. São Paulo: Summus, 2003.

MORAES, M. C. O paradigma educacional emergente. Campinas: Papirus, 1997.

NEVES, R. B. Integração da análise SWOT com o método electre tri na avaliação do desempenho de programas de pós-graduação. 2005. $203 \mathrm{f}$. Dissertação (Mestrado em Engenharia de Produção) - Universidade Federal Fluminense, Niterói, 2005.

NUNNALLY, J. C. Psychometric theory. New York: McGraw-Hill, 1978.

OWLIA, M. S.; ASPINWALL, E. M. Quality in higher education: a survey. Total Quality Management, Bradford, v. 7, n. 2, p.161-171, 1996.

PARRY, S. B. The guest for competencies. Training, Excelsior, v. 33, n. 7, p. 48-56, 1996.

PERRENOUD, P. Dez novas competências para ensinar. Porto Alegre: Artmed, 2000.

PESTANA, M.; GAGEIRO, J. Análise de dados para ciências sociais - A complementaridade do SPSS. Lisboa: Edições Sílabo, 2003.

RISTOFF, D. Universidade em foco. Florianópolis: Insular, 1999.

RUAS, R. Desenvolvimento de competências gerenciais e a contribuição da aprendizagem organizacional. In: FLEURY, M. T.; OLIVEIRA, J. M. (Org.). Gestão Estratégica do Conhecimento. São Paulo: Atlas, 2001.

SANT'ANNA, A. P. Modelagem da produtividade e gestão da qualidade acadêmica. Produção, São Paulo, v. 9, n. 2, p. 5-11, dez. 1999. 
SCHON, D. A. Educando o profissional reflexivo: um novo design para o ensino e aprendizagem. Porto Alegre: Artmed, 2000.

SGUISSARDI, V. O desafio da educação superior no Brasil: quais são as perspectivas? In: SGUISSARDI, V. Educação superior: velhos e novos desafios. São Paulo: Xamã, 2000.

TEJEDOR, F. J. Un modelo de evaluación del profesorado universitario. Revista de Investigación Educativa, Murcia, v. 21, n. 1, p. 157-182, 2003.

WALTER, S.; TONITINI, G.; DOMINGUES, M. Identificando oportunidades de melhoria em curso superior através da análise da satisfação dos alunos. In: ENCONTRO NACIONAL DE PROGRAMAS DE PÓSGRADUAÇÃO EM ADMINISTRAÇÃO, 29., 2005, Rio de Janeiro. Anais... Rio de Janeiro: ENANPAD, 2005. CD ROM.

ZÚÑIGA, R. La evaluación em La acción docente. In: APODACA, P.; LOBATO, C. Calidad em la Universidad: orientación y evaluación. Barcelona: Laertes, 1997.

ZARIFIAN, P. Objetivo competência: por uma nova lógica. São Paulo: Atlas, 2001. 